\title{
Influence of Multi-Beam Electron Beam Welding Technique on the Deformation of Ti6Al4V Alloy Sheet
}

\author{
Fan Jikang, Zhang Wei, Qi Bojin, Liu Fangjun
}

Beihang University, Beijing 100191, China

\begin{abstract}
Multi-beam electron beam welding (EBW) is a new technique that allows more than two electron beams running simultaneously for welding and it is considered a promising method to reduce welding stress and deformation. In order to reduce the deformation of Ti6A14V alloy sheets, a novel multi-beam EBW method was proposed in this research, including two additional electron beams to post-heat the weld, besides one main electron beam to melt metals. Experiments were conducted on Ti6Al4V alloy sheets using this multi-beam technique. Results show that compared with the conventional EBW, the multi-beam EBW can improve the welding thermal cycle and effectively reduce the welding deformation by adjusting the position and energy distribution of two additional electron beams.
\end{abstract}

Key words: multi-beam; welding deformation; electron beam welding; Ti6Al4V alloy

The low density, high specific strength, excellent high-temperature strength and good corrosion resistance of titanium alloys have led to a diversified range of applications in the aerospace, medical, automotive and nuclear industries $^{[1-3]}$. Ti6Al4V alloy is one of the most commonly used titanium alloys due to its excellent combination of above properties and it can be welded by several common fusion-welding processes such as electron beam welding (EBW), gas tungsten arc welding (GTAW) and laser beam welding (LBW). Among these welding processes, high vacuum EBW is a preferred technique. Firstly, as EBW is performed in vacuum, it can effectively prevent the titanium alloy from contamination of atmosphere gases. Secondly, EBW is capable of producing deep and narrow welds due to its high energy density and 'keyhole' effect. Moreover, EBW is a welding process with high heating and cooling rate and therefore can produce welds with minimal distortion ${ }^{[4]}$.

Multi-beam EBW is a new technique that allows more than two electron beams running simultaneously for welding and it is considered a promising method to reduce welding stress and deformation. In EBW, the electrons accelerated by high voltage have very high energy density, but they have almost no mass and are inertia free. Therefore they can be deflected by magnetic fields almost without time delay. Fig.1 shows the producing mechanism of multiple beams. Generally a set of deflecting coil is fixed under the focusing coil. When the focused electrons pass through the magnetic field produced by deflecting coils, they will have a specific deflection in very short time, so electrons can be divided into multiple beams visually ${ }^{[5]}$. With the high-frequency magnetic deflection system equipped in modern EBW machines, the multi-beam EBW technique becomes possible and the energy input and focus position of different beams could be adjusted flexibly, which allows to freely control the welding thermal process and in this way influence the welding deformation.

The multiple beams can be modulated to various forms, among which the following two modes shown in Fig. 2 are most common. First, electron beams can be modulated to generate multiple molten pools simultaneously to increase processing efficiency and reduce welding stress (Fig.2a); second, electron beams can be modulated to one main welding beam used to generate molten pool and several additional beams used to preheat or post-heat the workpiece (Fig.2b). In recent years, the multi-beam technique is developed and

Received date: September 25, 2016

Foundation item: Aeronautical Science Foundation of China (2014ZE51057)

Corresponding author: Zhang Wei, Ph. D., School of Mechanical Engineering and Automation, Beihang University, Beijing 100191, P. R. China, Tel: 0086-10-82338416, E-mail: zhangweibh@buaa.edu.cn 


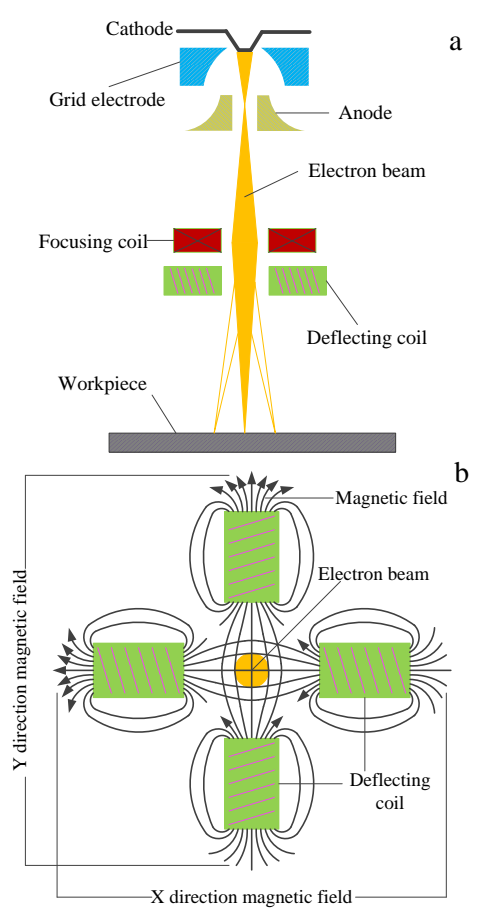

Fig.1 Producing mechanism of multiple electron beams in EBW: (a) configuration of electronic gun in EBW machine and (b) the deflecting system of EBW machine

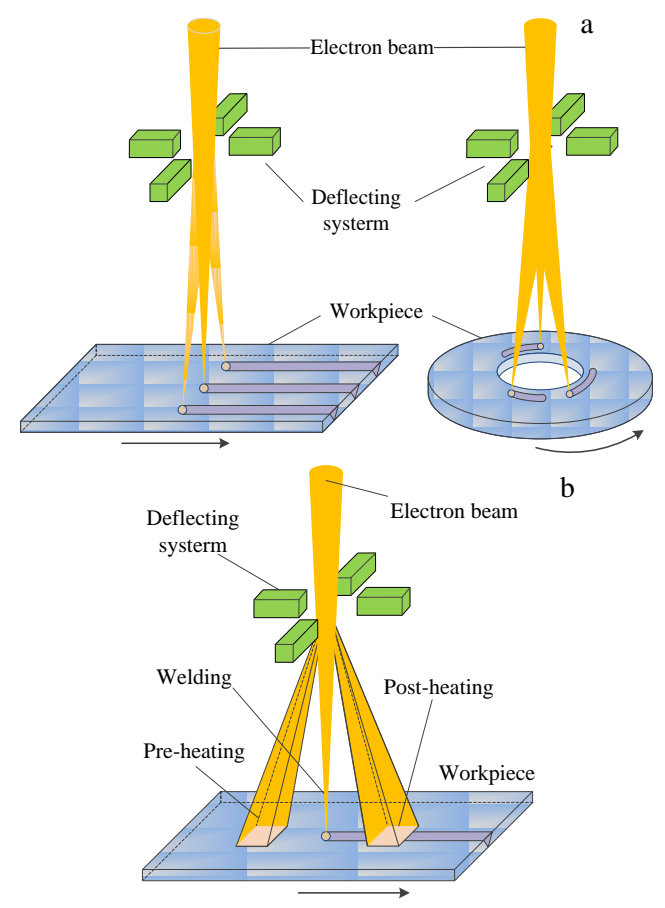

Fig.2 Two common forms of the multi-beam EBW technique: (a) electron beams used to generate multiple molten pools and (b) one main beam used to generate molten pool and several beams used to preheating and post-heating

applied in many industries ${ }^{[6]}$ and has been investigated by several researchers. C. J. Rosen found that the application of multi-beam technique for EBW local post-heat treatment provides an effective tool for reducing of residual stresses when welding thin sheet materials ${ }^{[7]}$. Sergii Krasnorutskyi developed multi-beam techniques by creating a series of weld pools simultaneously in order to produce high-quality welds on duplex stainless steel ${ }^{[8]}$. Clauß welded automobile gear boxes with three weld pools and diesel particle filters with 60 beam spots using the fast deflection and multi-beam technique ${ }^{[9]}$. Von Dobeneck D found that multiple beams can significantly reduce porosity by extending the cooling cycle ${ }^{[10]}$. Haiyan Zhao investigated the generation and the processes of multi-beams in EBW by both the numerical simulation methods and experiments, and the result shows that the residual stress of EBW could be minimized by the multiple beam technique ${ }^{[5]}$. However, as we know, the influence of multi-beam technique on the deformation of titanium alloy has not been researched.

Welding deformation is one of the most important problems in welding fabrication and how to reduce the welding deformation becomes an important research topic. In this research, for reducing the deformation of Ti6Al4V alloy sheet, a novel multi-beam EBW method was proposed including two additional electron beams to post-heat the weld, besides one main electron beam to melt metals. Experiments were conducted using this three-beam technique on Ti6Al4V alloy sheet by changing the position and energy distribution of two additional electron beams. After experiments, workpieces with less deformation were successfully welded, which proved multi-beam EBW can effectively reduce the welding deformation of Ti6Al4V alloy sheet.

\section{Experiment}

The $1 \mathrm{~mm}$ thick Ti6Al4V alloy sheets were chosen as the base metal and the chemical composition is given in Table 1 . The dimension of sheets is $300 \mathrm{~mm} \times 100 \mathrm{~mm}$. Before welding, they were cleaned with acid solution and then swabbed with ethanol in order to remove the surface metal oxides as well as other tarnishes.

In this research, the multi-beam technique was realized by one KS15 high-voltage vacuum EBW machine produced by PTR Corporation. The machine can precisely control the deflection position, the scanning pattern and the energy input of multiple beams and its deflecting holding time can correct to 1 us. The novel multi-beam EBW method is shown in Fig.3, which includes a focused main electron beam in ahead and two additional electron beams in the wings. Before conducting multi-beam experiments, repeated experiments were carried out to find the suitable parameters for welding $1 \mathrm{~mm}$ thick Ti6Al4V titanium alloy sheet with the conventional EBW. Parameter shown in Table 2 is acquired and the welded workpiece is shown in Fig.4. In the subsequent multi-beam EBW experiments, the welding parameters in Table 2 always remain the same. 
Table 1 Chemical composition of Ti6Al4V alloy sheet (wt\%)

\begin{tabular}{ccccccccc}
\hline $\mathrm{Ti}$ & $\mathrm{Al}$ & $\mathrm{V}$ & $\mathrm{Fe}$ & $\mathrm{Si}$ & $\mathrm{C}$ & $\mathrm{N}$ & $\mathrm{H}$ & $\mathrm{O}$ \\
\hline Bal. & $5.5 \sim 6.8$ & $3.5 \sim 4.5$ & 0.3 & 0.15 & 0.1 & 0.05 & 0.015 & 0.15 \\
\hline
\end{tabular}

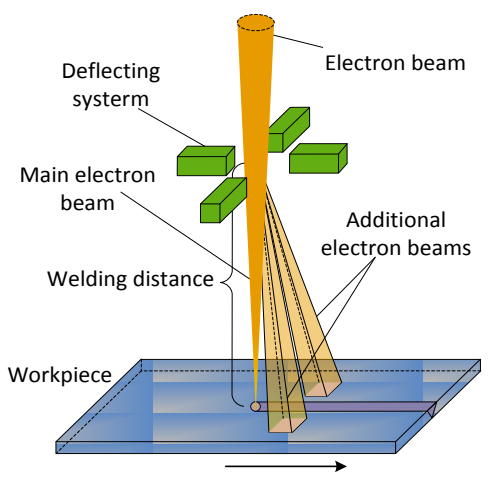

Fig.3 Schematic diagram of the novel multi-beam method in this research: one main electron beam used to melt metal and two additional electron beams used to post-heat the metal

Table 2 Welding parameters to weld $1 \mathrm{~mm}$ thick Ti6Al4V alloy sheet with conventional EBW

\begin{tabular}{ccccc}
\hline $\begin{array}{c}\text { Welding } \\
\text { distance } / \mathrm{mm}\end{array}$ & $\begin{array}{c}\text { Accelerating } \\
\text { voltage } / \mathrm{kV}\end{array}$ & $\begin{array}{c}\text { Welding } \\
\text { current } / \mathrm{mA}\end{array}$ & $\begin{array}{c}\text { Focus } \\
\text { current } / \mathrm{mA}\end{array}$ & $\begin{array}{c}\text { Velocity/ } \\
\mathrm{mm} \cdot \mathrm{s}^{-1}\end{array}$ \\
\hline 484 & 60 & 6.3 & 458 & 30 \\
\hline
\end{tabular}

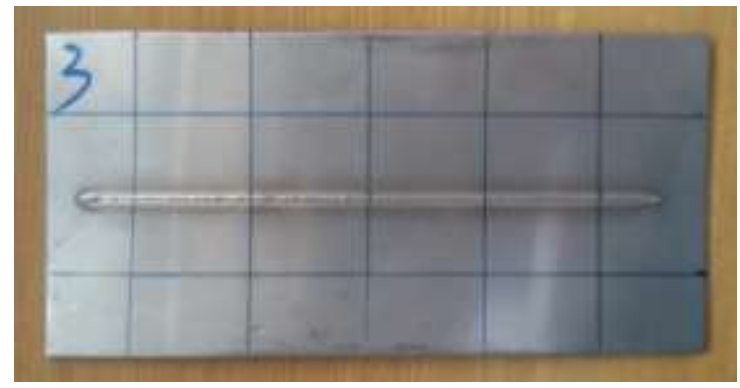

Fig.4 Workpiece welded by conventional EBW with parameters in Table 2

When conducting multi-beam EBW experiments, the two additional electron beams were symmetrically distributed in the wings and modulated to oblong shape. As shown in Fig.5, 'FH1' and 'FH2' are two auxiliary heat sources and ' $a$ ' and ' $b$ ' are the length and width of them, respectively. ' $D$ ' is the distance between the weld center and the oblong edge, and ' $H$ ' is the distance between the main electron beam and the oblong edge. In the experiments, ' $a$ ' and ' $b$ ' keep constant, $a=30 \mathrm{~mm}$, $b=15 \mathrm{~mm}$. while ' $D$ ' and ' $H$ ' could be adjusted freely according to the situation. In order to be consistent with the reference parameters in Table 2, all the multi-beam experiments must be carried out in the same welding energy input, namely keeping effective value of the main electron beam current equal to $6.3 \mathrm{~mA}$. For example, when the energy

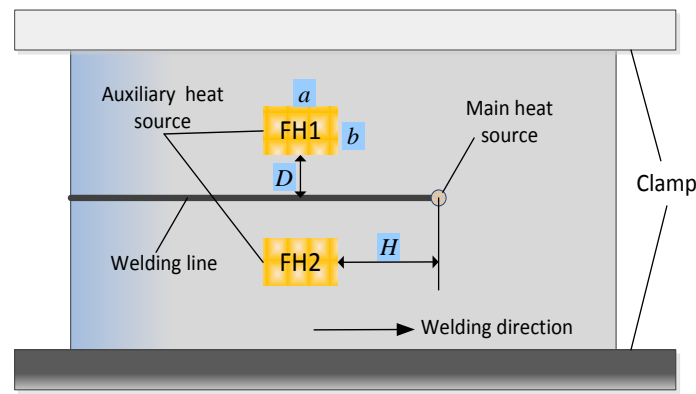

Fig.5 Schematic diagram of multi-beam welding parameters

proportion of two auxiliary heating sources accounted for $10 \%$ of the overall energy respectively, the total electron beam current should be increased to $8 \mathrm{~mA}$.

Welding deformation includes transverse shrinkage deformation, longitudinal shrinkage deformation, traverse bending deformation, longitudinal bending deformation, etc. Because longitudinal bending deformation is rather obvious than others, it was chosen as the evaluation criterion of welding deformation in this experiments. As shown in Fig.6, the longitudinal bending deformation was measured by a universal joint clamping dial indicator. Universal joint was fixed on a movable horizontal platform, so the vertical displacement of deformation could be measured by linearly moving the dial indicator or freely moving the workpiece. When the sheets bend upwards, we set the displacement positive, oppositely negative. Employing the measuring method, the average displacement of sheets welded by conventional EBW with parameters in Table 2 is $-19.7 \mathrm{~mm}$. Then experiments were carried out with different multi-beam parameters, which mainly include the distance ' $H$ ', ' $D$ ' and the energy distribution. For reducing errors, each experiment was repeated three times and we chose the average as the final result.

\section{Results and Discussion}

\subsection{Position of auxiliary heat sources}

The scanning size of oblong auxiliary heat sources was set

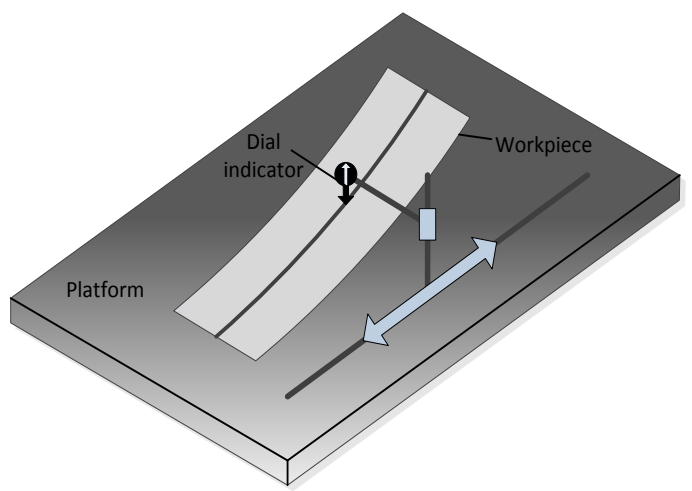

Fig.6 Measure equipment of longitudinal bending deformation 
$30 \mathrm{~mm} \times 15 \mathrm{~mm}$. When the energy input of additional electron beams accounted for $10 \%$ of the total energy with keeping $D=$ $5 \mathrm{~mm}$ unchanged, experiments were conducted on the Ti6Al4V alloy sheet in different ' $H$ ' condition. When $H=5$, $10,15 \mathrm{~mm}$, the deformation results are shown in Table 3.

As can be seen from Table 3, with the $H$ increasing, the amount of welding deformation decreases and then increases. And when $H=10 \mathrm{~mm}$, welding deformation reaches the minimum of $-11.3 \mathrm{~mm}$.

Table 3 shows that when $H=10 \mathrm{~mm}$, the deformation is smallest. So we keep $H=10 \mathrm{~mm}$ and the energy input of auxiliary heat sources unchanged. Then experiments were carried on the Ti6Al4V alloy sheet in different ' $D$ ' condition. When $D=0,5,10 \mathrm{~mm}$, the deformation results are shown in Table 4.

The Table 4 shows that, with the $D$ increasing, the amount of welding deformation decreases and then increases. When $D$ is $5 \mathrm{~mm}$, welding deformation reaches the minimum -11.3 $\mathrm{mm}$.

\subsection{Energy distribution of heat sources}

When $H=10 \mathrm{~mm}, D=5 \mathrm{~mm}$ and other parameters remain the same, the energy proportion of auxiliary heat sources 'FH1' and 'FH2' was changed in the following experiments. We set the energy proportion of conventional EBW as 0. Then experiments were conducted on the Ti6Al4V alloy sheet when auxiliary heat sources were in different energy proportions. The measured deformation results are shown in Table 5 .

As can be seen from Table 5, when the energy proportion of

Table 3 Deformation results in different ' $H$ ' condition

\begin{tabular}{cccc}
\hline \multirow{2}{*}{ Variable, $H / \mathrm{mm}$} & \multirow{2}{*}{ Sample } & \multicolumn{2}{c}{ Deformation, $\delta / \mathrm{mm}$} \\
\cline { 3 - 4 } & $1-1$ & -17.8 & \\
\hline \multirow{2}{*}{5} & $1-2$ & -17.9 & -17.9 \\
& $1-3$ & -18.0 & \\
\hline \multirow{2}{*}{10} & $2-1$ & -11.3 & \\
& $2-2$ & -11.1 & -11.3 \\
& $2-3$ & -11.5 & \\
\hline \multirow{2}{*}{15} & $3-1$ & -18.3 & -18.3 \\
& $3-2$ & -18.4 & \\
\hline
\end{tabular}

Table 4 Deformation results in different ' $D$ ' condition

\begin{tabular}{cccc}
\hline \multirow{2}{*}{ Variable, $D / \mathrm{mm}$} & Sample & \multicolumn{2}{c}{ Deformation, $\delta / \mathrm{mm}$} \\
\cline { 3 - 4 } & $4-1$ & -18.4 & \\
\hline \multirow{2}{*}{0} & $4-2$ & -18.2 & -18.2 \\
& $4-3$ & -18.0 & \\
& $2-1$ & -11.3 & -11.3 \\
5 & $2-2$ & -11.1 & \\
& $2-3$ & -11.5 & -18.6 \\
& $5-1$ & -18.7 & \\
\hline \multirow{2}{*}{10} & $5-2$ & -18.8 & \\
& $5-3$ & -18.3 & \\
\hline
\end{tabular}

Table 5 Deformation results in different energy proportion

\begin{tabular}{|c|c|c|c|c|}
\hline \multirow{2}{*}{$\begin{array}{c}\text { Energy } \\
\text { proportion/ } \\
\% \\
\end{array}$} & \multirow[b]{2}{*}{ Sample } & \multirow{2}{*}{$\begin{array}{c}\text { Total } \\
\text { current/mA }\end{array}$} & \multicolumn{2}{|c|}{ Deformation, $\delta / \mathrm{mm}$} \\
\hline & & & $\begin{array}{c}\text { Measured } \\
\text { value }\end{array}$ & $\begin{array}{c}\text { Average } \\
\text { value }\end{array}$ \\
\hline \multirow{3}{*}{0} & $6-1$ & & -19.5 & \\
\hline & $6-2$ & 6.3 & -19.8 & -19.7 \\
\hline & $6-3$ & & -19.8 & \\
\hline \multirow{3}{*}{10} & $2-1$ & & -11.3 & \\
\hline & $2-2$ & 8.0 & -11.1 & -11.3 \\
\hline & $2-3$ & & -11.5 & \\
\hline \multirow{3}{*}{15} & $7-1$ & & -4.6 & \\
\hline & $7-2$ & 9.0 & -4.6 & -4.5 \\
\hline & $7-3$ & & -4.3 & \\
\hline \multirow{3}{*}{16.25} & $8-1$ & & +2.4 & \\
\hline & $8-2$ & 9.3 & +2.0 & +2.2 \\
\hline & $8-3$ & & +2.2 & \\
\hline \multirow{3}{*}{17.5} & $9-1$ & & +10.7 & \\
\hline & $9-2$ & 9.7 & +10.5 & +10.5 \\
\hline & $9-3$ & & +10.3 & \\
\hline \multirow{3}{*}{20} & $10-1$ & & +19.5 & \\
\hline & $10-2$ & 10.5 & +19.6 & +19.5 \\
\hline & $10-3$ & & +19.4 & \\
\hline
\end{tabular}

auxiliary heat sources increases from 0 to $20 \%$, the total electron beam current also increased from $6.3 \mathrm{~mA}$ to $10.5 \mathrm{~mA}$ accordingly for the sake of maintaining the unity of welding parameters. With the increase of energy proportion, the welding deformation has a tendency to reduce, and when the proportion reaches $16.25 \%$, the workpiece starts to bend upwards and has the smallest deformation. But when the energy proportion continues to increase, the welding deformation bending upwards continued to increase.

The experimental results show that the position and energy distribution of auxiliary heat sources are the main influence factors of welding deformation and with appropriate multi-beam EBW parameters, the welding deformation of Ti6Al4V alloy sheet can be reduced effectively.

\subsection{Results discussion}

Deformation in a weld structure is the result of the inconsistent expansion and contraction of the weld and surrounding base material, caused by the nonuniform heating and cooling during welding process ${ }^{[11]}$. Improving the welding thermal cycle and reducing the thermal stress are effective methods to reduce the welding deformation. In the research, when two auxiliary heating sources 'FH1' and 'FH2' are used to post-heat the just welded Ti6Al4V titanium alloy sheet, the temperature of the weld will decrease more slowly, which can reduce the welding stress. In order to realize the temperature variation of the welding process in multi-beam EBW, we simulated the welding thermal process using a combined heat source model with the ANSYS software. The temperature curve at $0,1,2,12.5 \mathrm{~mm}$ (the distance of additional sources) in the transverse direction was detected. Some results are shown in Fig.7. Compared with the conventional EBW, the 

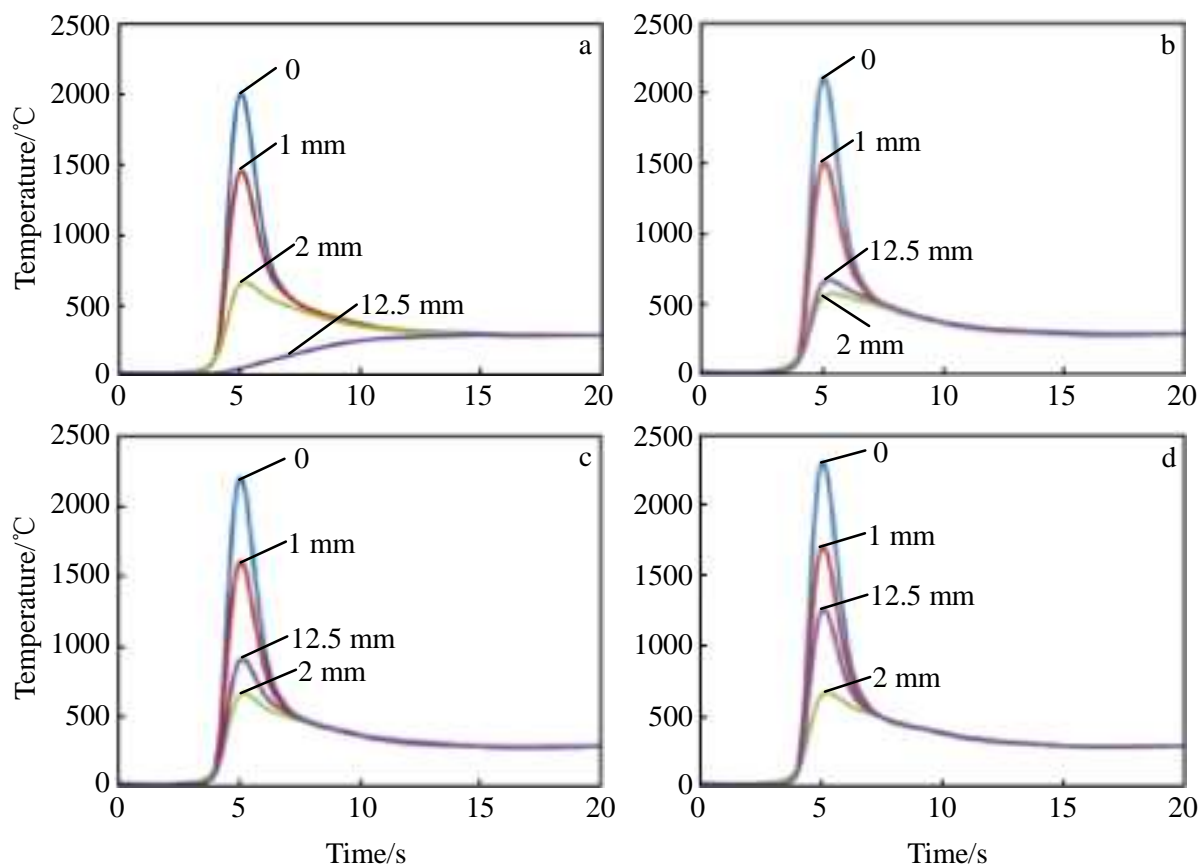

Fig.7 Temperature curves in the transverse direction: (a) conventional EBW (sample 6), (b) energy proportion 10\% (sample 2), (c) energy proportion $16.5 \%$ (sample 8 ), and (d) energy proportion $20 \%$ (sample 10)

temperature near the weld in multi-beam welding has little difference, but the temperature near the auxiliary heat sources has a significant increase because of the post-heating. And with the increase of energy proportion of auxiliary heat source, the temperature increases remarkably. Therefore, owing to the temperature variation caused by the post-heating beams, thermal stresses in the weld can also be rectified to reduce the deformation.

Welding thermal stress is the direct cause of deformation. In the multi-beam EBW, the welding thermal stresses can be decreased after the combined effect of multiple beams. As shown in Fig.8, when the main heat source welds the workpiece, the major thermal stress will be produced accordingly. And when the auxiliary heat sources post-heat the workpiece, the thermal stress will be produced too. Because the whole welding process in multi-beam EBW welding is an integration process, two kinds of thermal stress caused by different beams will produce combined effect, which reduce both the peak value of tension and compression stress. Therefore the welding deformation can be reduced too. In this way, the deformation can be reasonably reduced by adjusting multi-beam parameters appropriately. As shown in Table 3 and 4, when the distance between auxiliary heating sources and welding pool is too far, the combined effect of welding stresses is too weak to reduce the deformation effectively. With the distance shortened, the peak values of compression stress affected by auxiliary heating sources and tension stress affected by main heating source will overlap at one location and cancel out each other; therefore the welding thermal stress

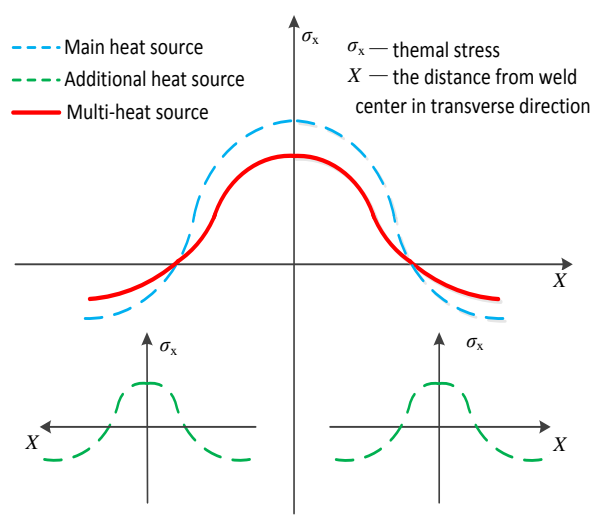

Fig.8 Thermal stresses caused by multi-beam welding

and deformation will be both reduced. When $D=5 \mathrm{~mm}$ and $H=10 \mathrm{~mm}$, the combined effect of stresses is most obvious and the deformation is smallest.

As we can see from Table 5, with the increase of energy proportion of auxiliary heating sources, the heat input used for post-heating will increase, so the thermal stress caused by auxiliary heating sources increases too, while the heat input of main heating source is constant, namely the magnitude and distribution of thermal stress caused by main heating source are constant. Therefore the summation of welding stresses will decrease and the deformation will decrease accordingly. When the energy proportion is $15 \%$ and welding current is $9 \mathrm{~mA}$, the tension stress caused by the main heat source is neutralized by the compression stress caused by the auxiliary heat sources to 
maximum extent, so the deformation decreased to $-4.5 \mathrm{~mm}$. When the energy proportion increases to $16.25 \%$, and the welding current was $9.3 \mathrm{~mA}$, the workpiece started to bend upward and the displacement of deformation reaches the minimum $2.2 \mathrm{~mm}$. This is because that, with the increase of energy input of auxiliary heating sources, the summation of all thermal stress around the weld center begins to change from tensile stress to compressive stress. However, with the further increase of the energy input, the compressive stress and deformation of Ti6Al4V alloy sheet gradually increase too.

The above results focus on the relationship of multi-beam parameters and titanium alloy sheet deformation. But in order to further reveal the controlling mechanism of deformation on the Ti6Al4V alloy sheet with multi-beam EBW, there is more work to do. In the next stage, the specific changing law of the welding thermal field and stress will be quantitatively studied by both experiments and computer simulations.

\section{Conclusions}

1) The novel multi-beam EBW method proposed is an effective method to control the welding deformation of Ti6Al4V alloy sheet. The heat sources position and energy distribution of additional electron beams are the main influence parameters.

2) By adjusting the position and energy distribution of two auxiliary sources in multi-beam EBW, the welding deformation of $1 \mathrm{~mm}$ thick Ti6Al4V alloy sheet can be reduced remarkably. When the welding current is $9.3 \mathrm{~mA}$,
$D=5 \mathrm{~mm}, H=10 \mathrm{~mm}$ and the energy proportion is $16.25 \%$, the deformation reaches the minimum $2.2 \mathrm{~mm}$.

\section{References}

1 Karimzadeh F, Salehi M, Saatchi A et al. Materials and Manufacturing Processes[J], 2005, 20: 205

2 Casalino G, Curcio F, Memola F et al. Journal of Materials Processing Technology[J], 2005, 167: 422

3 Wang S H, Wei M D, Tsay LW. Materials Letters[J], 2003, 57: 1815

4 Balasubramanian T S, Balasubramanian V, Manickam M A M. Materials \& Design[J], 2011, 32: 4509

5 Zhao Haiyan, Wang Xin, Wang Xichang et al. Frontiers of Materials Science in China[J], 2008, 2(1): 66

6 Fu Pengfei, Mao Zhiyong, Lin Jian et al. Vacuum[J], 2014, 102: 54

7 Rosen C J, Gumenyuk A, Zhao H et al. Science and Technology of Welding and Joining[J], 2007, 12(7): 614

8 Sergii Krasnorutskyi, Helge Pries, Manuela Zinke et al. Welding in the World[J], 2013, 57: 487

9 Clauß U, Bull J. International Conference on Power Beam Processing Technologies (ICPBPT2010)[C]. Beijing: Aviation Manufacturing Technology Press, 2010: 125

10 von Dobeneck D. International Symposium on High Energy Density Beam Processing Technology[C]. Kunming: Aviation Manufacturing Technology Press, 2004: 18

11 Dean Deng, Hidekazu Murakawa. Computational Materials Science[J], 2008, 43: 353

\title{
多束流电子束焊接对 Ti6Al4V 钛合金薄板变形的影响
}

\author{
范雯康, 张 伟, 齐铂金, 刘方军 \\ (北京航空航天大学, 北京 100191)
}

\begin{abstract}
摘 要: 多束流电子束焊是一种能够同时产生多个电子束流作为焊接热源的电子束焊接新技术, 能够有效的减小焊接应力和变形。为了 减小 Ti6Al4V 钛合金薄板焊接变形, 提出了一种新型的多束流电子束焊接技术，除了熔化金属的主束流外，还包括 2 个对称分布的辅助 束流用来焊后加热。分别用传统电子束焊和多束流电子束焊对 $1 \mathrm{~mm}$ 厚的 Ti6Al4V 钛合金薄板进行焊接试验, 试验表明, 通过调节 2 个 辅助束流的位置和能量分布, 多束流电子束焊能够有效减小钛合金薄板的焊接变形。
\end{abstract}

关键词：多束流；焊接变形；电子束焊接；Ti6Al4V 铁合金

作者简介: 范雯康, 男, 1988 年生, 博士生, 北京航空航天大学机械工程及自动化学院, 北京 100191, 电话: 010-82338416, E-mail: fanjk@buaa.edu.cn 